\title{
Post traumatic epilepsy: there is still much to learn
}

\author{
Epilepsia pós traumática: ainda há muito a aprender \\ Guilherme S. MENDONC,A', , Josemir W. SANDER ${ }^{2,3}$
}

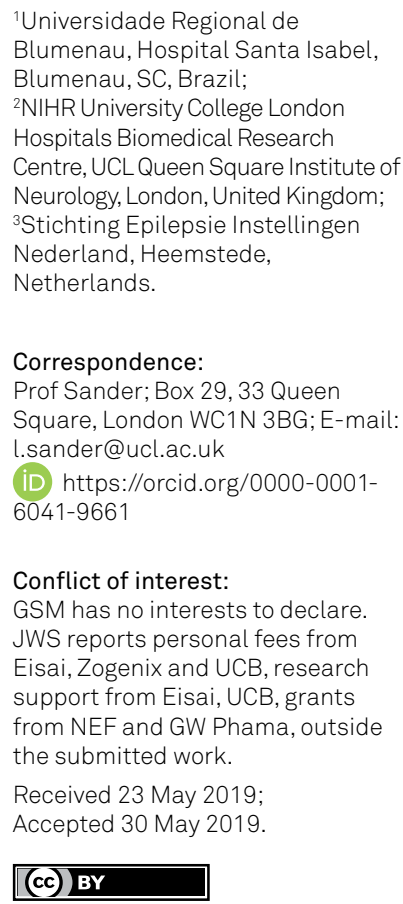

1 Universidade Regional de Blumenau, Hospital Santa Isabel, Blumenau, SC, Brazil;

${ }^{2}$ NIHR University College London Hospitals Biomedical Research Centre, UCL Queen Square Institute of Neurology, London, United Kingdom; ${ }^{3}$ Stichting Epilepsie Instellingen Nederland, Heemstede, Netherlands.

Correspondence:

Prof Sander; Box 29, 33 Queen Square, London WC1N 3BG; E-mail: l.sander@ucl.ac.uk (iD) https://orcid.org/0000-00016041-9661

Conflict of interest:

GSM has no interests to declare. JWS reports personal fees from Eisai, Zogenix and UCB, research support from Eisai, UCB, grants from NEF and GW Phama, outside the submitted work. Received 23 May 2019; Accepted 30 May 2019.

(cc) BY

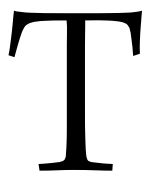
raumatic brain injury (TBI) is one of the most common causes of death and motor disability mainly in people under the age of 40 years but also in senior citizens ${ }^{1}$. TBI numbers have steadily increased over the years and have now reached epidemic proportions ${ }^{1,2}$. This, however, is not well recognised and TBI has recently been described as the silent or hidden epidemic ${ }^{1}$. In addition to high mortality, TBI produces hardship on individuals and their families as well as being a major societal burden. TBI when not fatal often leads to the incapacity of young people which directly generates public health expenditure and, over a life time, incurs major indirect costs particularly in terms of social benefits ${ }^{1,2,3,4}$.

Epidemiological data on TBI vary throughout the world in terms of demographics and causality. Recent data suggest a first incidence peak between the ages of 20 and 30 years and a second peak in those over 60 years old ${ }^{3,4}$. Common causes include road traffic accidents, violence, falls, occupational hazards in the building and farming industries, domestic accidents and contact sports ${ }^{1,3,4}$. Alcohol overindulgence seems to be a major risk factor ${ }^{3}$. The incidence of TBI seems to correlate with social development and the poorer the country the greater the number of fatal accidents. A recent development seems to be that the rapid deployment of two-wheeled vehicles in some resource-poor settings has led to local epidemics of $\mathrm{TBI}^{1}$. In view of the most common causes, it is not surprising that TBI is much more frequent in males ${ }^{1,3}$.

An increase in the prevalence of acute symptomatic epileptic seizures has been observed recently, with TBI being one of the main causes ${ }^{4.5}$. Studies have already confirmed that central nervous system injuries such as ischemic or haemorrhagic stroke, cerebral anoxia, brain infection, brain inflammation, autoimmune diseases and degenerative diseases are all associated with evolution to epileptic seizures either acute seizures but also late seizures ${ }^{3.4}$. By definition TBI is the only direct risk factor for Post-Traumatic Epilepsy (PTE) and this risk is well known. One of the many outstanding issues is, however, if acute or early seizures are enhancers of the risk and by which factor.

The definitions for post-trauma seizures usually used are: immediate (occurring within 24 hours), early (within the first 7 days) and late (occurring after 7 days). According to the International League Against Epilepsy (ILAE) an isolated late unprovoked seizure associated with a known traumatic brain injury now fulfils the criteria for epilepsy ${ }^{6,7}$. Using this new definitions some case series have established an $80 \%$ risk of seizure recurrence over the two initial years following cranial trauma with a late post-traumatic seizure ${ }^{6}$ although not all of these recur to conform to the old definition of epilepsy (of two unprovoked epileptic seizures at least 24 hours apart). Overall epidemiological data suggest that the risk is higher in the first 6 months, but remains increased for up to 10 years. There seems to be a higher relative risk of epilepsy in women and in those with a family history of epilepsy ${ }^{4}$ which are likely to be telling us something in regards to the biology and the genetic predisposition to epilepsy.

In this issue of the journal, Liu et al report on risk factors and prognosis related to early epileptic seizures after trauma (EPTE) $)^{8}$. This is important as it may increases further the risk of PTE over the years. The incidence of TBI in the young and the elderly is increasing and PTE is one of the few preventable forms of epilepsy ${ }^{1,2,3,4}$. So the work of Liu et al is topical. They gathered data on a number of individuals (186) with traumatic head injury. This was then analysed 
in a cross-sectional fashion; the work was well planned and has some interesting data. Clinical data included the clinical history, neurological examination, imaging and electroencephalography ${ }^{8}$. The subjects were divided into two groups (non-EPTE and EPTE). The Glasgow Outcome Scale (GOS) and the Activity of Daily Living Scale (ADL) were used to assess outcome and quality of life ${ }^{1}$.

According to Liu et al, the occurrence of EPTE is closely related to the location of cranial trauma, the type of trauma and the severity of the injury ${ }^{8}$. Epilepsy was more prevalent in individuals with brain damage in the parietal lobe and temporal lobe regions ${ }^{8}$. The parietal lobe is near the central anterior / posterior gyrus of the cerebral cortex and electrical activity is more frequent in this region than in other areas, with a lower threshold for epileptic seizures ${ }^{6}$. Temporal trauma results in synaptic disruption in the hippocampus, a region associated with epileptic seizures ${ }^{1}$. In addition, Liu et al confirm that open cranial trauma is more strongly associated with early epileptic seizures post trauma than closed trauma ${ }^{8}$. Accidents with severe brain damage are much more likely to be associated with abnormal cortical neuronal discharges, possibly leading to epilepsy, than milder accidents ${ }^{1}$.

The work of Liu et al provides, therefore, some further pieces to the puzzle but also leaves us with the clear realisation that there are still many unanswered questions. For instances, how do we assess whether the epileptic seizure was related to the trauma, or whether the individual already had a pre-disposition to seizures? For some, the question actually is, "was the TBI the result of a first seizure?" particularly when an event is unwitnessed. There are also still many glitches in our knowledge in terms of prognostic indicators.

Epidemiological and genetic risk factors are not yet fully understood, and secondary preventative treatment is currently not possible. The only way to avoid PTE at this time is with the primary prevention of brain injuries which could be argued is easier said than done. We should not only investigate the full epidemiological profile of TBI which is important for the development of primary preventative measures, but also genetic predisposition at different stages, epilepsy prophylaxis ( for those individuals at risk of PTE) and personalised treatments to improve the quality of life of those who already have PTE. Further work is therefore imperative to solve the puzzle in full.

\section{ACKNOWLEDGMENTS}

This work was done at NIHR University College London Hospitals Biomedical Research Centre, which receives a proportion of funding from the UK Department of Health's Research Centres funding scheme. JWS receives research support from the Marvin Weil Epilepsy Research Fund, the UK Epilepsy Society, and the Christelijke Vereniging voor de Verpleging van Lijders aan Epilepsie, The Netherlands.

\section{References}

1. Roozenbeek B, Maas Al, Menon DK. Changing patterns in the epidemiology of traumatic brain injury. Nat Rev Neurol. 2013 Apr;9(4):231-6. https://doi.org/10.1038/nrneurol.2013.22

2. GBD 2016 Traumatic Brain Injury and Spinal Cord Injury Collaborators. Global, regional, and national burden of traumatic brain injury and spinal cord injury, 1990-2016: a systematic analysis for the Global Burden of Disease Study. Lancet Neurol. 2019 Jan;18(1):56-87. https://doi.org/10.1016/S1474-4422(18)30415-0

3. Tagliaferri F, Compagnone C, Korsic M, Servadei F, Kraus J.A systematic review of brain injury epidemiology in Europe. Acta Neurochir (Wien). 2006 Mar;148(3):25568. https://doi.org/10.1007/s00701-005-0651-y-

4. Christensen J. The Epidemiology of posttraumatic epilepsy. Semin Neurol. 2015 Jun;35(3):218-22. https://doi.org/10.1055/s-0035-1552923
5. Lowenstein DH. Epilepsy after head injury: an overview. Epilepsia. 2009 Feb;50 Suppl 2:4-9. https://doi.org/10.1111/j.1528-1167.2008.02004.x

6. Fisher RS, Emde Boas W, Blume W, Elger C, Genton P, Lee P, et al. Epileptic seizures and epilepsy: definitions proposed by the International League Against Epilepsy (ILAE) and the International Bureau for Epilepsy (IBE). Epilepsia. 2005 Apr;46(4):4702. https://doi.org/10.1111/j.0013-9580.2005.66104.x

7. Fisher RS. An overview of the 2017 ILAE operational classification of seizure types. Epilepsy Behav. 2017 May;70(Pt A):271-3. https://doi.org/10.1016/j.yebeh.2017.03.022

8. Liu ZM, Chen QX, Chen ZB et al. Clinical analysis on risk factors and prognosis of early post-traumatic epilepsy. Arq Neuropsiquiatr. 2019;77(6):375-80. https://doi.org/10.1590/0004-282X20190071 